GLÁUKS

\title{
Entrevista com Marcos Siscar
}

Joelma Santana Siqueira (Universidade Federal de Viçosa)

Vivaldo Andrade dos Santos (Georgetown University)

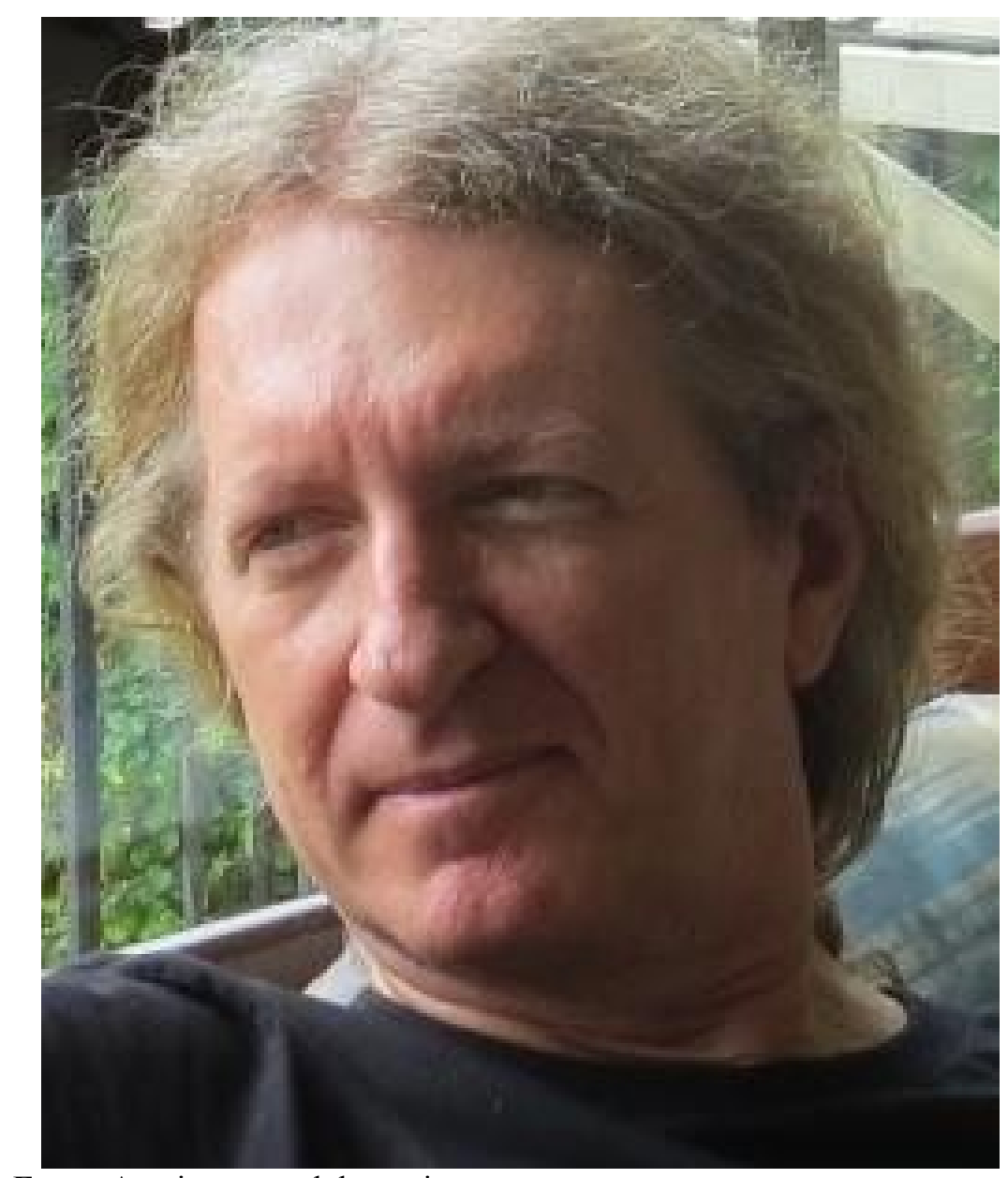

Fonte: Arquivo pessoal do escritor.

Marcos Siscar é poeta, tradutor, professor da Unicamp e pesquisador do CNPq. É autor de Jacques Derrida: rhétorique et philosopohie (1998), Poesia e crise (2010) e De volta ao fim (2016, prêmio Jabuti), entre outros livros de ensaio. Traduziu autores como Tristan Corbière,

Gláuks: Revista de Letras e Artes-jul/dez. 2020 - v. 20, n. 2 
Félix Fénéon, Michel Deguy, Jacques Roubaud e Samuel Beckett. Seus livros de poesia incluem Metade da Arte (2003), O roubo do silêncio (2006), Interior via satélite (2010), Manual de flutuação para amadores (2015) e Isto não é um documentário (2019). Tem livros traduzidos e poemas publicados em revistas e antologias na Alemanha, Argentina, Bélgica, Espanha, França, EUA, Hungria, Inglaterra e Portugal.

\section{Prezado Marcos Siscar,somos muito gratos a você por nos conceder essa entrevista para o presente dossiê da Gláuks dedicado ao tema "A literatura brasileira no exterior". Para iniciarmos, pedimos que nos fale sobre como é escrever e publicar literatura no Brasil.}

Eu é que agradeço a possibilidade de conversar com vocês e, indiretamente, com os leitores da revista Gláuks. Tenho muito interesse pelo gênero da entrevista, que dá uma forma bastante concreta à ideia de interlocução e de endereçamento - questão importante para quem escreve.

Bem, as dificuldades de se dedicar à literatura são muito conhecidas. Elas não são exclusivas do Brasil, mas há certamente uma mitologia do sucesso como escritor (que vem desde o século XIX, pelo menos) e que expõe mais rapidamente suas ilusões quando aplicada a um mercado de livros relativamente modesto como o brasileiro. A precariedade econômica, a baixa escolaridade, a pouca importância que é dada à leitura e à literatura, são entraves para a circulação de livros. Haveria exceções a mencionar, é claro. Mas quase sempre elas nos encaminhariam para a autoajuda, a literatura infanto-juvenil, o roteiro, certa prosa de ficção, áreas com uma relação mais clara com o mercado, com o cinema, com o audiovisual.

Como escrevo poesia, não diria que a situação é mais grave, mas é certamente mais complexa. Ao lado da questão econômica e educacional que a afeta, a poesia se presta também a um debate relacionado com a tradição erudita. Se, por um lado, é identificada ao elitismo "hegemônico" (o que tem impacto direto na reformulação dos conteúdos curriculares, por exemplo), por outro lado é subestimada como fenômeno que "já não interessa a

Gláuks: Revista de Letras e Artes-jul/dez. 2020 - v. 20, n. 2 
ninguém". Ou seja, é combatida como lugar de poder, com o argumento supostamente democrático da falta de interesse. A meu ver, esse discurso transforma o que deveria ser uma conquista da educação em um privilégio, ou em um anacronismo. E o que vale para a poesia, em particular, vale também para a literatura (na sua relação com a categoria genérica da "leitura"), ainda que de modo mais indireto, ainda não muito bem dimensionado. Como também sou professor universitário, essa é uma situação discursiva que me interessa e que me preocupa.

Escrevo desde a adolescência e venho de um ambiente familiar de baixa educação formal e meios bastante modestos de subsistência. Por isso, sempre soube que precisava ter outra atividade para sobreviver. A poesia me encaminhou para a faculdade de Letras e esta para a carreira universitária. Dediquei muitos anos à minha formação acadêmica, o que ajudou a expandir meu repertório de leituras. Só publiquei meu primeiro livro aos 34 anos, quando considerei que tinha uma escrita pessoal mais definida. É possível enxergar essa trajetória como uma convergência bem sucedida entre o exercício da escrita e a vida prática, ou entre a poesia e a crítica. Mas também é verdade que a carreira universitária é extremamente exigente, o que limita bastante a possibilidade de desenvolver meus projetos literários.

Enviei meu primeiro livro de poemas (Não se diz) para a Editora 7Letras a convite de Carlito Azevedo, que era o responsável pela recém criada revista Inimigo Rumor. A exemplo deste primeiro, venho publicando meus livros sempre a convite de editores, aproveitando a generosa disponibilidade que me oferecem (é o caso, especialmente, de Jorge Viveiros de Castro, da Editora 7Letras). Nessas duas décadas, fui conhecendo outros poetas e pessoas envolvidas na discussão universitária ou no mercado editorial, o que me permitiu ter uma visão mais abrangente sobre a vida literária no Brasil. Ainda que a distribuição dos meus livros seja muito precária, como acontece com boa parte da produção literária brasileira, posso dizer, então, que venho encontrando as condições adequadas para fazer o que me interessa, que é escrever meus poemas e vê-los bem editados.

Gláuks: Revista de Letras e Artes - jul/dez. 2020 - v. 20, n. 2 
2. Você considera que há diferenças que mereçam ser destacadas entre a recepção que sua obra tem no Brasil e a que tem no exterior?

Estou sendo entrevistado como um escritor brasileiro e, especificamente, como disse, "poeta brasileiro". Então, há dois aspectos a se levar em consideração na recepção da obra: o fato de se tratar de poesia, e o fato de se tratar de literatura brasileira.

É preciso lembrar que a opção pela poesia tem consequências importantes no modo de publicação e circulação. O interesse pela poesia é mais restrito, no caso das editoras tradicionais, por uma questão de mercado. E por isso a edição de autor, as pequenas tiragens e, em especial, a opção pela divulgação do trabalho em revistas literárias assumem importância bem maior do que em outros gêneros. Nesse sentido, as condições de recepção no Brasil e no exterior me parecem semelhantes, em termos de suporte, embora as situações sejam sempre mais complexas quando se trata, não apenas de poesia, mas de poesia traduzida.

Tenho alguns livros traduzidos no exterior e poemas publicados em antologias e revistas, principalmente na Europa. Em determinados casos, por proximidades que são de ordem geopolítica, mas também cultural, a recepção fora do país me parece ter maior consistência. Eu citaria aqui o acolhimento do que escrevo na Argentina ou em Portugal. Em Portugal, é claro, isso ocorre em função da língua e do passado em comum, dos interesses mútuos que se estabelecem mais facilmente entre poetas de mesma língua.

Certo sentimento de proximidade se dá também, embora por razões distintas, com relação a países vizinhos, como a Argentina, país com o qual o Brasil vem fazendo trocas crescentes de natureza artística e intelectual (por exemplo, na universidade). Isso acaba por exercer um impacto direto em termos de iniciativas de tradução e em termos de qualidade da leitura. A primeira tradução de um livro meu de poesia foi feita lá (No se dice, em 2003, por Aníbal Cristobo). Mais recentemente, tive também um livro de ensaios traduzido e publicado naquele país (Poesia y crisis, 2019, por Luciana di Leone).

Em todos os casos, mas sobretudo em países que falam outra língua, a circulação do poeta brasileiro depende em primeiro lugar do engajamento de determinados tradutores ou editores, cujo esforço encontra ou não eco com o público, dependendo do modo como esse grupo se articula e transita localmente. Se há, é claro, obras de brasileiros publicadas sem a

Gláuks: Revista de Letras e Artes-jul/dez. 2020 - v. 20, n. 2 
marca da nacionalidade (como as de Paulo Coelho, para citar um exemplo), na maior parte do tempo o contato com a literatura escrita em um país periférico como o Brasil depende do interesse pelos temas e problemas brasileiros, por questões relacionadas a seu espaço cultural ou aos estereótipos da nacionalidade.

Isso não é necessariamente verdadeiro no outro sentido. Embora as relações sejam sempre marcadas por projeções mútuas, é possível dizer que há um fluxo de tradução de autores da Europa e da América do Norte que não chega ao Brasil com esse carimbo do particularismo. Não de maneira tão imediata. O interesse de um autor estrangeiro, lido no Brasil, não se liga tanto ao fato de tratar de temas canadenses, ou italianos, ou austríacos. Isso tem a ver com vários fenômenos, inclusive é claro com o funcionamento do mercado internacional de livros e o interesse midiático pelos best-sellers. Mas não custa lembrar que, de modo geral, quando um escritor brasileiro é traduzido no exterior, como disse, sua leitura é mediada pela "realidade brasileira" ou pela "cultura brasileira". Poucos escapam a isso, e por razões bem precisas, por outros tipos de determinação que, em determinado momento, se sobrepõem (é o caso da leitura feminista de Clarice Lispector, por exemplo).

Então, para concluir, creio que a recepção do que escrevo é completamente diferente, no Brasil e no exterior. Embora, naturalmente, me interesse bastante a circulação do que escrevo fora do país (porque ali também estão em jogo determinados modos de leitura, determinadas formas de consolidação de leituras), tenho consciência de que meus "contemporâneos", no sentido forte dessa palavra, são majoritariamente brasileiros; de que escrevo para leitores brasileiros ou para leitores que têm algum tipo de relação forte com o destino dessa língua e desse espaço cultural.

\section{Qual a importância da tradução, sobretudo, para o escritor que escreve em português?}

A tradução é um verdadeiro pharmakon (remédio e veneno) para a difusão mais ampla de uma obra. Ela é necessária para sua internacionalização (é o "remédio" para a

Gláuks: Revista de Letras e Artes - jul/dez. 2020 - v. 20, n. 2 
idiossincrasia do enraizamento linguístico), mas é também um problema que angustia todos aqueles ciosos da "fidelidade" ao original.

Claro que a situação muda muito, de língua para língua. E sua pergunta já insinua parte do problema: embora seja relevante em termos globais, do ponto de vista da quantidade de falantes, o português não é das línguas mais prestigiadas literariamente.

Um autor dos EUA ou da Irlanda sabe que seu público leitor pode vir a ser bem mais amplo que o do seu país (inclusive maior que o conjunto de países de língua inglesa), já que o inglês é uma língua relativamente internacionalizada. Escrever em português (como em sueco ou em turco) é ter certeza de que (com exceções muito pontuais) só será lido fora de seu país pela via da tradução. No cálculo sobre a abrangência que uma obra brasileira pode ter, a tradução é, portanto, elemento decisivo da equação. Mais do que necessária, como disse antes, às vezes a iniciativa da tradução se confunde com a própria iniciativa da publicação.

Se acrescentarmos às questões linguísticas e geopolíticas a situação específica da tradução especificamente poética, temos uma situação ainda mais delicada. Numa prática de escrita como a poesia, mais propositalmente idiomática e experimental, a possibilidade de encontrar um tradutor em sintonia com os dispositivos da obra original é bem menor.

Naturalmente (e até com certa frequência), o tradutor é ele próprio um poeta. Por outro lado, quanto mais bem sucedida é a tradução de poesia, mais o texto em língua estrangeira tende a se vincular à obra do poeta tradutor, cada vez menos à obra do poeta traduzido. Não chega a causar espanto que traduções de outros poetas feitas por Samuel Beckett apareçam no volume de sua poesia completa; da mesma forma, aceita-se com naturalidade que Haroldo de Campos inclua traduções em seus próprios livros de poesia.

\section{Quais são os desafios para ser publicado no exterior ou ser traduzido para outra língua?}

Como decorrência do que disse até agora, observo que não é simples um livro de poesia brasileira ser traduzido e publicado no exterior, mesmo quando falamos de obras que

Gláuks: Revista de Letras e Artes-jul/dez. 2020 - v. 20, n. 2 
fizeram algum sucesso por aqui; e os critérios que estão na origem dos livros efetivamente publicados nem sempre são compreensíveis.

Creio que vem dessas dificuldades o relativo descompasso que sentimos ao entrar em contato com a edição de poesia brasileira fora do país. Num certo momento, na França, havia pouquíssimas traduções de poetas brasileiros, um ou outro grande nome do Modernismo, como Bandeira e Drummond, ao lado de edições pontuais de autores sem o mesmo tipo de representatividade.

Muita coisa vem mudando. Mas é importante notar que, mesmo no caso de poetas importantes da produção mais recente (como, por exemplo, Haroldo de Campos ou Ana Cristina Cesar), a tradução e a edição continua sendo, como disse, fruto do empenho dos próprios tradutores (de Inês Oseki-Dépré, no caso de Haroldo; ou de Michel Riaudel, no caso de Ana Cristina Cesar). A lógica da edição de poesia é menos a do esforço de disponibilizar o que já fez provas de qualidade e relevância (embora isso também ocorra) do que o exercício contínuo - próximo de uma espécie de "diplomacia" cultural - que é o de divulgar e fazer conhecer, junto com a obra de determinado poeta, a própria ideia de "poesia brasileira".

\section{5. "Traduttore, traditore". Como é ler sua obra traduzida para outro idioma? Destacaria algum exemplo?}

Se me coloco no lugar de quem vai ser traduzido, tenho duas expectativas principais: a primeira é que o tradutor se disponha a compreender as coisas que escrevi, de preferência no contexto mais amplo do livro (quiçá da obra); a segunda expectativa é que, na sintonia mais profunda com esse contexto, ele se disponha a reinventar meus poemas em sua língua, dando solução poética às figuras e aos elementos formais envolvidos.

Isso, evidentemente, requer alguma dedicação e quantidade de trabalho improváveis na vida de um tradutor de poesia que, a exemplo do próprio poeta, não sobrevive apenas desse ofício. Então, no fundo, tais princípios valem mais como horizonte do que como exigência. A regra é outra e as exceções se baseiam, como sabemos, quer seja nas motivações pessoais do

Gláuks: Revista de Letras e Artes - jul/dez. 2020 - v. 20, n. 2 
tradutor, quer seja em apoios institucionais específicos para a realização de determinados trabalhos.

Vejo com bastante simpatia a simples notícia de tradução dos meus textos para outras línguas. É preciso lembrar que, na maior parte dos casos, não tenho proficiência suficiente nos idiomas em que os textos são reescritos. Há casos, é claro, em que consigo identificar a natureza de determinadas opções, eventualmente algum problema (em geral, de compreensão). Porém, para interagir de modo mais consequente com o que acontece com um texto em outra língua seria necessário conhecer essa língua, ter uma boa noção de seu uso, de seus registros, de sua tradição literária. Nesse sentido mais básico, dada a barreira linguística, não é tão simples responder à pergunta "como é ler sua obra traduzida".

A relação mais próxima que tenho com uma língua estrangeira é com o francês, por ter vivido alguns anos na França e realizado parte da minha formação universitária naquele país. Sou capaz de perceber nuanças de escrita literária em francês, embora nem sempre seja capaz de produzi-las. Resulta disso que não tenho total autonomia para traduzir meus textos, mas que posso ter uma boa ideia do que ocorre na tradução.

Acresce que, como já tive tradutores diferentes para meus textos, a comparação facilita o discernimento. De um trabalho a outro, observam-se diferentes níveis de conhecimento do português, diferentes capacidades de leitura de poesia e de familiaridade com o que escrevo. Eu destacaria, nesse sentido, o trabalho de Michel Riaudel, que é leitor experiente e profundo conhecedor da literatura brasileira.

O que eu poderia citar como experiência particular e relevante em termos de processo foi o trabalho de tradução que fizemos, Raymond Bozier e eu, a quatro mãos, de $O$ roubo do silêncio (Le rapt du silence, publicado na França em 2007). Nem eu tinha total proficiência do francês, nem ele conhecia bem o português. O que acabou acontecendo foi uma experiência muito significativa de diálogo, de compreensão dos limites, não apenas das línguas, mas também das diferenças impostas pela cultura, pela tradição literária, pela realidade física e cotidiana. Se traduzir é reinserir um texto em outro lugar, recontextualizá-lo, por assim dizer, então a tradução é uma operação de extrema complexidade: não só os contextos não são intercambiáveis, como também não são saturáveis, ou seja, não são conjuntos acabados e disponíveis, mesmo para quem participa deles. Então, ao invés de pensar na tradução como

Gláuks: Revista de Letras e Artes-jul/dez. 2020 - v. 20, n. 2 
transporte, recontextualização, seria mais exato dizer que traduzir é estabelecer uma relação na qual está em jogo determinado envolvimento com os contextos (o de partida e o de chegada).

O trabalho que acabo de mencionar foi muito rico nesse sentido. Conversamos sobre diferenças de visão de poesia e sobre diferenças linguísticas. Se conseguimos encontrar pontos de encontro nessas operações de leitura, observamos também inúmeras dificuldades e bloqueios. E, até para não ocultar a natureza do processo, resolvemos deixar no texto uma marca ostensiva do caráter conflituoso da tradução: mantivemos a palavra "carrapicho" (imagem importante em alguns poemas) no texto em francês - um pouco como às vezes se mantém a palavra "sertão" em traduções de Guimarães Rosa ou Euclides da Cunha. É o máximo da "fidelidade" (à obra original) e, ao mesmo tempo, o máximo da "traição" (em relação ao contexto ao qual se destina), uma espécie de cicatriz de tradução, memória de uma perigosa imersão na diferença.

\section{Existe uma "literatura nacional", presa a um país, a uma região, a uma língua?}

Creio que existe sempre um contexto editorial, um contexto linguístico, um contexto histórico, um contexto político e geopolítico no qual o escritor está inserido. E que esse contexto precisa ser pensado, em sua complexidade. Minha interlocução mais imediata, como disse, é com um leitor que me lê em português, mas não me sinto limitado especialmente pelo critério nacional. Traduzo e estudo literatura estrangeira, questões de literatura estrangeira, tentando pensar como elas incidem sobre minha experiência particular e sobre minhas interlocuções. Escrevo preocupado com o que está à minha volta, mas não escrevo como se só existisse a literatura brasileira; tampouco como se a "literatura brasileira" fosse um corpo acabado, a ser conservado nas suas fronteiras e nas suas referências mais conhecidas.

Não é uma situação simples, portanto. Creio que é preciso dar atenção crítica bem definida ao contemporâneo, calcular os efeitos de diálogo e os efeitos de bloqueio que se estabelecem com outros "contextos". Da mesma forma, num outro campo de razões, também não podemos esquecer que "literatura" e "brasileiro" são termos potencialmente equívocos,

Gláuks: Revista de Letras e Artes-jul/dez. 2020 - v. 20, n. 2 
suscetíveis a efeitos de trânsito que desafiam sua pureza. Isso ocorre não apenas pelo fato da tendência cosmopolita e humanística da cultura erudita, que nos faz acreditar que Fernando Pessoa ou Wislawa Szymborska devem ser lidos de modo semelhante a Carlos Drummond de Andrade ou Hilda Hilst. Trata-se de observar que abstrações como "literatura" e "brasileiro", com tudo o que têm de importante e de representativo, sob vários aspectos, também se assentam sobre exclusões - o que nos levaria a repensar, por exemplo, o estatuto das manifestações não escritas, ou das manifestações socialmente marginais ou marginalizadas.

São duas ordens de problemas que estão em jogo. Uma delas é a da permeabilidade do nacional em relação àquilo que o excede, linguisticamente ou geograficamente. Outra é a da legitimidade dos alicerces sobre os quais está fundado. Percebo aliás que, na prática, cada vez mais o compromisso com aquilo que antes era chamado "local" tem se deslocado para regiões políticas não coincidentes com o dispositivo da "nação", no sentido tradicional. Questões como raça, gênero, exclusão cultural, entre outras, tendem a abrir outro viés de relação com a literatura e com a localidade, transformando seus sentidos e seus valores. De maneira que muitas vezes, paradoxalmente, esses debates acabam colocando em xeque a própria ideia de literatura, na sua concepção mais tradicional ("nacional” ou "internacional”).

Sinto-me sensível a essas causas ditas "identitárias", embora não acredite que haja uma discussão possível para a questão da literatura que a conceba como um único bloco, de sentido coeso e acabado. Ou seja, é preciso sempre analisar, de maneira cuidadosa, suas assimetrias: suas referências, suas obras, seu passado. Passar a discutir literatura como um todo determinado a partir de imperativos que a excedem é o caminho mais curto para esmagar suas diferenças, homogeneizá-la, quer seja a fim de contorná-la, quer seja para colocar outra coisa em seu lugar.

\section{Seu fazer literário busca responder a alguma urgência presente na realidade social brasileira que você gostaria de destacar?}

A escrita literária me interessa naquilo que ela tem de radical como experiência da linguagem. Naturalmente, a linguagem também diz respeito à "realidade social", uma vez que essa expressão precisa ser preenchida por um conteúdo que é um conteúdo discursivo.

Gláuks: Revista de Letras e Artes - jul/dez. 2020 - v. 20, n. 2 
Quem lê meus textos provavelmente sente dificuldade em encontrar as temáticas relacionadas com a dita "realidade social brasileira". É claro que ali estão, embora nem sempre se mostrem à primeira vista. Quase sempre aparecem transfiguradas: não exatamente simuladas, mas transformadas em figuras. Ou seja, me interessa explorar essas questões como acontecimentos da vida comum; me interessa associá-las a outras camadas da percepção do mundo, mudando a escala e a qualidade dessa observação, de modo que aquilo que é uma "urgência" pontual da perspectiva do cidadão civil (que também sou) pode se tornar um elemento de interpretação poética das coisas.

Muitas vezes, é pelo viés da experiência de um sujeito (entendida como "pessoal") ou pelo pensamento comparativo (entendido como "metafórico") que as urgências da realidade social podem se tornar perceptíveis poeticamente. Para dar um exemplo recente: num certo momento, senti necessidade de falar do "golpe" (político) e acabei por explorar a expressão "sentir o golpe", que coloca em jogo não apenas a situação de violência política, mas também a violência simbólica da relação com o outro, a quebra do pacto, o sentimento de estranhamento em relação a determinada comunidade.

Não costumo associar a minha escrita com temas sociais específicos, como quem olha de fora da realidade circundante e elabora um julgamento sobre ela. Não creio que cabe à poesia disputar espaço com o jornalismo ou com os diversos fluxos de discurso social na tarefa de informar ou de mobilizar as pessoas para a transformação regulada de determinadas práticas. Prefiro me referir às situações cotidianas do modo como elas chegam até mim e me afetam. Entram aí os acontecimentos coletivos de grande impacto, naturalmente, os sofrimentos cotidianos, não apenas por referência a situações socialmente dadas, mas também por observação dos faits divers em aparência banais, notícias anódinas, discursos sociais retirados de seu contexto etc. É um material muito heterogêneo, que está impregnado pelas questões contemporâneas, pelas dores que às vezes estão dadas como coletivas e às vezes só são coletivas por parecerem particulares. Esse material me interessa à medida que passa pelo crivo dos meus sentidos, das minhas figuras, por uma inteligência poética que se relaciona com o espanto que temos diante da violência e da injustiça.

Em suma, não pretendo me colocar como filtro (soberano ou sintomático) de depuração da realidade, mas como ponto de refração dessa realidade. Trata-se de deixar

Gláuks: Revista de Letras e Artes-jul/dez. 2020 - v. 20, n. 2 


\section{GLÁUKS}

emergir os conflitos e os impensados que fundamentam nossa relação tensa com o presente. Tampouco suponho que meus leitores sejam capazes de refazer todo esse raciocínio, mas creio que a maior parte dos que estão habituados a ler poesia não têm dificuldade com esse modus operandi.

Gláuks: Revista de Letras e Artes-jul/dez. 2020 - v. 20, n. 2 